\title{
Application of Graphene Hybrid Materials in Fault Characteristic Gas Detection of Oil-Immersed Equipment
}

\author{
Lingfeng Jin ${ }^{1,2,3}$, Weigen Chen ${ }^{1,2 *}$ and Ying Zhang ${ }^{3 *}$ \\ ${ }^{1}$ State Key Laboratory of Power Transmission Equipment \& System Security and New Technology, Chongqing University, \\ Chongqing, China, ${ }^{2}$ School of Electrical Engineering, Chongqing University, Chongqing, China, ${ }^{3}$ School of Electrical and \\ Computer Engineering, Georgia Institute of Technology, Atlanta, GA, United States
}

Graphene and its hybrid materials, due to their unique structures and properties, have attracted enormous attention for both fundamental and applied research in the gas sensing field. This review highlights the recent advances in the application of graphene-based gas sensors in fault characteristic gas detection of oil-immersed equipment, which can effectively achieve condition monitoring of the oil-immersed power equipment. In this review, the synthetic methods of graphene hybrid materials with noble metals, metal oxides and their combination are presented. Then, the basic sensing

OPEN ACCESS

Edited by:

Zhongchang Wang,

Laboratório Ibérico Internacional de Nanotecnologia (INL), Portugal

Reviewed by:

Ming-Guo Ma,

Beijing Forestry University, China

Chunli Zhang,

Zhejiang University, China

*Correspondence:

Weigen Chen

weigench@cqu.edu.cn

Ying Zhang

yzhang@gatech.edu

Specialty section:

This article was submitted to

Nanoscience,

a section of the journal

Frontiers in Chemistry

Received: 22 June 2018

Accepted: 20 August 2018

Published: 11 September 2018

Citation:

Jin L, Chen W and Zhang Y (2018)

Application of Graphene Hybrid

Materials in Fault Characteristic Gas

Detection of Oil-Immersed Equipment.

Front. Chem. 6:399.

doi: $10.3389 /$ fchem.2018.00399 mechanisms of graphene hybrid materials and gas sensing properties of graphene hybrid materials sensors to hydrogen $\left(\mathrm{H}_{2}\right)$, carbon monoxide $(\mathrm{CO})$, carbon dioxide $\left(\mathrm{CO}_{2}\right)$, methane $\left(\mathrm{CH}_{4}\right)$, acetylene $\left(\mathrm{C}_{2} \mathrm{H}_{2}\right)$, ethylene $\left(\mathrm{C}_{2} \mathrm{H}_{4}\right)$, and ethane $\left(\mathrm{C}_{2} \mathrm{H}_{6}\right)$, which are the fault characteristic gas in oil-immersed power equipment, are summarized. Finally, the future challenges and prospects of graphene hybrid materials gas sensors in this field are discussed.

Keywords: graphene, gas sensor, oil-immersed equipment, sensing mechanism, fault characteristic gas

\section{INTRODUCTION}

Graphene is an allotrope of carbon consisting of a single layer of carbon atoms arranged in a hexagonal lattice, which was rediscovered, isolated, and characterized by Geim and Novoselov in 2004 (Novoselov et al., 2004; Geim and Novoselov, 2007). Owing to the unique structure, graphene exhibits excellent physical and chemical properties, and has opened a new and very promising scientific area with a lot of focus on material science and potential applications (Aïssa et al., 2015; Higgins et al., 2016; Long et al., 2018). Among these outstanding properties of graphene, the high electron mobility of up to $200,000 \mathrm{~cm}^{2} / \mathrm{Vs}$ and superior specific surface area of $2,630 \mathrm{~m}^{2} / \mathrm{g}$ make graphene an extremely sensitive material for gas detection (Akturk and Goldsman, 2008; Chen et al., 2008; Bonaccorso et al., 2015). However, pristine graphene, which lacks dangling bonds, is unfavorable for the adsorption of gas molecules on its surface. Therefore, the modification of graphene and its derivatives via physicochemical methods, such as covalent, non-covalent and doping functionalization, has been investigated. Usually, graphene hybrid materials, which are composed of graphene and typical sensing materials (e.g., noble metals, metal oxides, or their ternary hybrids), have significantly improved performance due to the synergistic interaction between graphene and the typical sensing material (Meng et al., 2015). There have been numerous works published on the basic research and the sensing applications of graphene and graphene hybrid materials. 
One such application is condition monitoring of oil-immersed equipment. Insulating oil with high specific heat and dielectric strength is widely used in the high voltage power equipment. However, the insulating oil can be cracked into small related gas molecules due to the long-term electrothermal effect, which reduces the insulation strength and leads to the malfunction of the power equipment. According to previous studies, effective detection of seven typical fault characteristic gases, including $\mathrm{H}_{2}, \mathrm{CO}, \mathrm{CO}_{2}, \mathrm{CH}_{4}, \mathrm{C}_{2} \mathrm{H}_{2}, \mathrm{C}_{2} \mathrm{H}_{4}$, and $\mathrm{C}_{2} \mathrm{H}_{6}$, can reflect the operation state of oil immersed power equipment (Bakar et al., 2014). Recently, a lot of research has been carried out on using graphene hybrid materials to detect these gases for rapid and accurate fault detection of oil-immersed equipment (Acharyya and Bhattacharyya, 2016; Zhou et al., 2016; Nasresfahani et al., 2017; Zhang et al., 2017b).

Although there are many reviews on the applications of gas sensing using graphene materials (Wang T. et al., 2016; Singhal et al., 2017; Dai et al., 2018), few has focused on detecting the typical gases reflecting the characteristics of faults in oilimmersed equipment. The objective of this review is to provide researchers a systematic understanding of the development of graphene hybrid materials in this application field. The main synthesis method and properties of graphene hybrid materials are introduced in section Synthesis, Properties, and Experimental Testing. Then, the gas sensing mechanism of graphene hybrid materials is discussed in section Sensing Mechanism. In section Application of Gas Sensor, the gas sensing properties of graphene hybrid materials to typical fault characteristic gases of oilimmersed equipment are summarized and compared. Finally, we analyze the challenges of gas sensing application in this field and present the suggestions of the future development trend.

\section{SYNTHESIS, PROPERTIES, AND EXPERIMENTAL TESTING}

\section{Synthesis and Properties}

Since the discovery of graphene in 2004, a lot of research has been conducted on how to synthesize graphene with high quality and large scale. To this date, the preparation of graphene can be mainly divided into top-down routes and bottom-up routes. Top-down routes use graphite as raw materials, and graphene is mainly obtained through separating the carbon atom layer by mechanical exfoliation, chemical oxidation-reduction reaction, and electrochemical methods. In contrast, bottom-up routes use small carbon-based molecules as raw materials, and graphene is obtained by silicon carbide pyrolysis, chemical vapor deposition (CVD), and solvothermal methods. Paton et al. (2014) developed a simple model that shows exfoliation occurs once the local shear rate exceeds $10^{4} / \mathrm{s}$ and demonstrated a scalable method for producing relatively large quantities of defectfree graphene. Rathnayake et al. (Yola et al., 2015) presented the methods for preparing graphene oxide (GO) and reduced graphene oxides ( $\mathrm{rGO}$ ) using chemical oxidation and reduction processes, respectively, which are based on needle platy variety of natural vein graphite that has high purity and crystallinity and low cost. Hofmann et al. (2015) investigated the process of electrochemical exfoliation and the impact of its parameters on the produced graphene, and achieved the synthesis of graphene with controllable electronic and mechanical characteristics. Son et al. (2015) reported direct graphene growth over silicon nanoparticles without silicon carbide formation, and the volumetric energy densities are 972 and $700 \mathrm{Wh} / \mathrm{L}$ at the first and 200th cycles, respectively. Banszerus et al. (2015) showed that the quality of CVD-grown graphene depends critically on the used transfer process and reported an advanced transfer technique that allows both reusing the copper substrate of the CVD growth and making devices with mobilities as high as $350,000 \mathrm{~cm}^{2} / \mathrm{Vs}$. Quan et al. (2014) successfully synthesized sulfur-doped and nitrogendoped graphene by using a solvothermal method, and these heteroatom-doped graphene materials exhibited high surface areas and high contents of heteroatoms. With the synthetic routes mentioned above, controllable preparation of graphene can be achieved.

Graphene as an ideal base material can be combined with noble metals, metal oxides, or their ternary hybrids to form graphene hybrid materials with outstanding gas sensing properties. Metal nanoparticles combine the excellent properties of metal and characteristics of nanomaterials, and show great potential in catalysis, sensing and electronics fields. Up to now, nanoparticles of many different metals, such as $\mathrm{Au}, \mathrm{Ag}$, $\mathrm{Pd}, \mathrm{Pt}, \mathrm{Cu}, \mathrm{Ni}, \mathrm{Co}$, have been successfully combined with graphene. Phan et al. (in press) synthesized Pt nanoparticleloaded $3 \mathrm{D}$ graphene for $\mathrm{H}_{2}$ sensing using a polymer-assisted hydrothermal method and the $\mathrm{H}_{2}$ sensor had a response value of $16 \%$ and response/recovery times of $9 / 10 \mathrm{~s}$ with a $1 \% \mathrm{H}_{2}$ concentration at $200{ }^{\circ} \mathrm{C}$. Semiconductor metal oxide such as $\mathrm{SnO}_{2}$ (Wang et al., 2015), $\mathrm{ZnO}$ ( $\mathrm{Zhu}$ and Zeng, 2017), $\mathrm{TiO}_{2}$ (Zhang et al., 2018), etc. are used widely in gas detection. The hybrids of graphene and metal oxides are mainly prepared by insitu synthesis, liquid phase method and hydrothermal method. Ye et al. (2015) developed porous graphene embedded with various types of metal oxide nanoparticles through direct laser scribing on the metal-complex-containing polyimide film. Zhang B. et al. (2017) prepared $\mathrm{rGO} / \alpha-\mathrm{Fe}_{2} \mathrm{O}_{3}$ hybrids with different rGO contents, which were composed of the round-edged cubic $\alpha-\mathrm{Fe}_{2} \mathrm{O}_{3}$ particles adhering uniformly on both sides of the crumpled and rippled rGO sheets. The local p-n heterojunctions between n-type $\alpha-\mathrm{Fe}_{2} \mathrm{O}_{3}$ and p-type rGO caused an extension of electron depletion layer and potential barriers, which in turn led to significant resistance variation. Zhou et al. (2017) synthesized $\mathrm{rGO}$ and $\mathrm{rGO} / \mathrm{ZnO}$ thin films and the performances of sensing organic vapor molecules are enhanced. In order to combe the advantages of noble metal and metal oxide, the ternary graphene hybrid materials have been developed. Uddin et al. (2015a) synthesized an $\mathrm{Ag} / \mathrm{ZnO} / \mathrm{rGO}$ hybrid via photochemical method and the $5 \mathrm{wt} \%$ hybrid enhanced the $\mathrm{C}_{2} \mathrm{H}_{2}$ sensing performance. Wei et al. (2017) synthesized the composite of $\mathrm{Ag} / \mathrm{SnO}_{2} / \mathrm{rGO}$ via a hydrothermal reaction process with a high surface area of $191.583 \mathrm{~m}^{2} / \mathrm{g}$ and showed enhanced sensing properties to ethanol. Esfandiar et al. (2014) synthesized $\mathrm{Pd} / \mathrm{WO}_{3} / \mathrm{rGO}$ as hybrid sensing material via the facile hydrothermal method and an improvement in $\mathrm{H}_{2}$ sensing at low temperatures was observed. 


\section{Sensor Fabrication and Testing}

Graphene hybrid materials can be used to fabricate gas sensors. Based on the operating mode, the device structure of gas sensor can be classified into directly heated and indirectly heated types. For a directly heated sensor, the sensing materials are in direct contact with the heater, which may make the sensor lose its stability and anti-interference ability. Therefore, the indirectly heated sensors are most widely used in scientific research and commerce, as shown in Figure 1B. The planar gas sensor is usually composed of three layers: sensing materials, detection electrodes and substrate (Nguyen et al., 2014). The synthesized sensing materials are covered by the detection electrodes. The interdigital electrodes are used to measure the resistance of the sensing materials. The substrate, made of silicon or alumina, has a good compatibility with integrated circuits and can support the sensing materials.

The responses of the sensor to different gases are carried out by using the gas sensing experimental platform, which composed of gas sources, MFCs (mass flow controllers), testing chamber and computer-controlled data acquisition and analysis system, as presented in Figure 1A. The experimental procedure is as follows: firstly, the sensor is placed in the center of the heating stage with two adjustable probes. Then, the heater starts to work and the background gas is delivered into the sealed chamber with a constant speed. When the resistance of the sensor no longer changes, the test chamber is filled with a different concentration of the gas being tested. At last, the background gas will be delivered again after the response of the sensor becomes stable. The response of sensor can be defined as a function of the change of resistance value of sensor (Barsan and Weimar, 2003). All the experiments need to be carried out under the same ambient temperature and relative humidity.

\section{SENSING MECHANISM}

Schedin et al. reported that the graphene gas sensor can effectively detect the adsorption or dissociation behavior of a single gas molecule on the surface of graphene, due to the fact that the change of carrier concentration of graphene leads to the change in electrical conductivity (Schedin et al., 2007). Meanwhile, due to the existence of oxygen functional groups, GO and rGO usually show better sensing properties than graphene. When GO or rGO are exposed to the air, the oxygen functional groups of them mainly combine $\mathrm{H}_{2} \mathrm{O}$ molecules with hydrogen bonds and the adsorbed $\mathrm{H}_{2} \mathrm{O}$ molecules are transferred to $\mathrm{H}_{3} \mathrm{O}^{+}$, further promoting the formation of ion channels on the surface of the sample. When they are in contact with adsorbed molecules, the hydrogen bonds will be destroyed, which inhibits the ionization reaction between oxygen functional groups and $\mathrm{H}_{2} \mathrm{O}$ molecules and leads to step-like changes in resistance (Ozcan et al., 2018). Prezioso et al. (2013) prepared a p-type gas sensor through GO drop-cast on standard interdigitated Pt electrodes and its sensing properties to $\mathrm{NO}_{2}$ was analyzed. They also presented the sensing mechanism of the gas sensor: when $\mathrm{NO}_{2}$ molecules adsorbed on the oxygen functional groups, the electrons of the adsorption sites are transferred to $\mathrm{NO}_{2}$ molecules, which leads to the decrease of electron concentration in the surface of the sensing materials, giving a reason for the p-type behavior.

In general, the sensing mechanisms of graphene hybrid are analyzed from the following three aspects. First, the introduction of nanoparticles can effectively prevent the aggregation of graphene sheets, thereby the graphene hybrid material is more favorable to form a 3D porous nanostructure with higher specific surface area, and more adsorption sites, vacancies, defects, and $\mathrm{sp}^{2}$-bonded carbon, which are beneficial to the adsorption of gas molecules (Russo et al., 2012; Zhang et al., 2015a). Secondly, the formation of $\mathrm{p}-\mathrm{n}$ heterojunctions between graphene and metal/metal oxide enhances the gas sensing properties. Once the target gas molecules are in contact with these interfaces, the depletion layers at the heterojunctions will be modulated, the electron state will be changed, and the phenomenon of charge transfer is more active, which lead to a larger relative change of resistance of graphene hybrid material (Tran et al., 2014). Thirdly, when hybrid materials contain metal oxide (e.g., $\mathrm{SnO}_{2}$, $\mathrm{ZnO}, \mathrm{CuO}, \mathrm{Co}_{3} \mathrm{O}_{4}$ ), the sensing behavior can be explained by the surface-adsorbed oxygen (Bai et al., 2015). For n-type metal oxide material, the oxygen molecules $\mathrm{O}_{2 \text { (gas) }}$ will capture electrons from the surface of metal oxide to form chemisorbed oxygen species $\left(\mathrm{O}_{2}^{-}, \mathrm{O}^{-}\right.$, or $\left.\mathrm{O}^{2-}\right)$, which leads to a high resistance of the sensor, as observed in the experiments (Jin et al., 2016). As shown in Figure 1C, when the sensor is exposed to reducing gas such as methane, the target gas molecules will react with chemisorbed oxygen species and obtain electrons from them, which reduces the concentration of electron on the surface of the sensing materials. Obviously, the gas sensing reaction is a ticklish issue associated with the intricate nanostructure and complicated sensing mechanism (Wang et al., 2011; Sun et al., 2015; Wang Z. et al., 2016). The research on the characterization methods and simulation analysis from atomic level provide a new perspective and starting point for the study on the sensing mechanism of nanomaterials.

\section{APPLICATION OF GAS SENSOR}

Graphene hybrid materials exhibit excellent sensing properties to $\mathrm{H}_{2}, \mathrm{CO}, \mathrm{CO}_{2}$, and small hydrocarbon gas (e.g., $\mathrm{CH}_{4}, \mathrm{C}_{2} \mathrm{H}_{2}, \mathrm{C}_{2} \mathrm{H}_{4}$, $\mathrm{C}_{2} \mathrm{H}_{6}$ ). In this section, we summarize and discuss the related works based on the recently published papers (Table $\mathbf{1}$ ).

\section{Hydrogen}

The amount of $\mathrm{H}_{2}$ in the insulating oil will increase significantly before the electrical fault or thermal failure occurs. Therefore, online monitoring of the $\mathrm{H}_{2}$ content can ensure the security and stability of operation of oil immersed equipment. Noble metal is known for its high superior selectivity for the adsorption of $\mathrm{H}_{2}$ due to its catalytic activity for $\mathrm{H}_{2}$ molecules. The gas sensor based on Pd (Alfano et al., 2017) or Pt (Harley-Trochimczyk et al., 2015) nanoparticles loaded graphene demonstrated high sensitivity to $\mathrm{H}_{2}$ with short response and recovery time. Sharma and Kim (2018) fabricated a MEMS $\mathrm{H}_{2}$ sensor based on Pd$\mathrm{Ag} /$ graphene, which showed a detection limit of $500 \mu \mathrm{L} / \mathrm{L}$ due to the phase transition of $\mathrm{Pd}-\mathrm{Ag}$. In addition, as metal oxide exhibits excellent gas sensing properties for $\mathrm{H}_{2}$, the graphene-metal oxide 


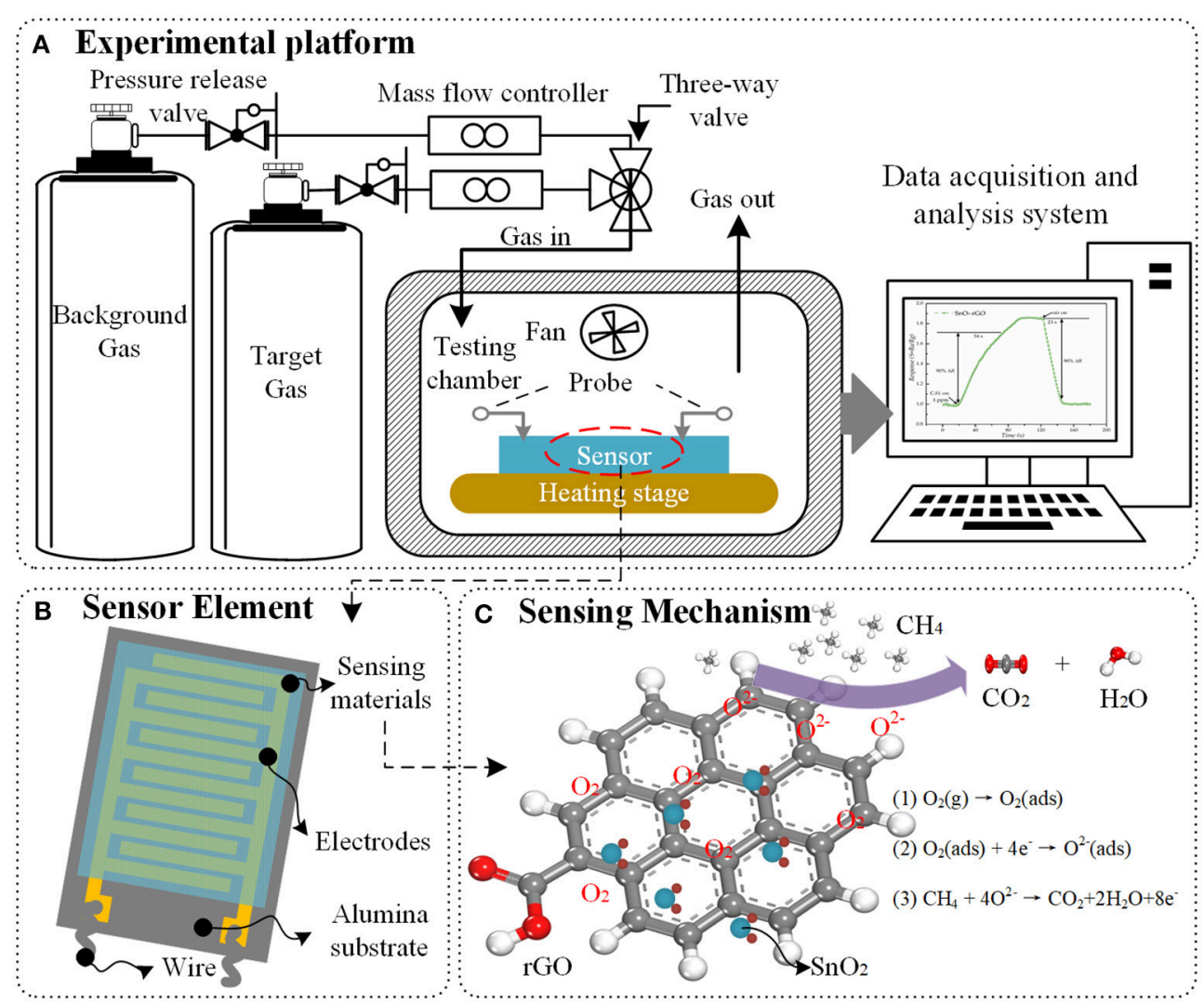

FIGURE 1 | Schematic illustration of (A) gas sensing experimental platform, (B) structure of planar sensor element, and (C) sensing mechanism between $\mathrm{SnO}_{2} / \mathrm{rGO}$ hybrid materials and methane.

hybrid materials are usually used to detect $\mathrm{H}_{2}$ with low limit of detection (LOD) at room temperature. Wang et al. synthesized $\mathrm{MoO}_{3}$ nanoribbon/graphene hybrid for $\mathrm{H}_{2}$ sensing with ultralow LOD of $0.5 \mu \mathrm{L} / \mathrm{L}$ (Yang et al., 2017). Zhang et al. (2017c) reported a high-performance $\mathrm{H}_{2}$ gas sensor based on $\mathrm{CuO} / \mathrm{rGO} / \mathrm{CuO}$ sandwiched nanostructure. Chen and co-workers successfully fabricated a device based on gasochromic- $\mathrm{Pd} / \mathrm{WO}_{3} /$ graphene/ $\mathrm{Si}$ tandem structure with fast response and recovery time for $\mathrm{H}_{2}$ (Chen et al., 2018).

\section{Carbon Monoxide and Carbon Dioxide}

$\mathrm{CO}$ and $\mathrm{CO}_{2}$ are mainly associated with the presence of overheating fault, which are decomposed from the cellulose of insulating oil paper. Consequently, development of highperformance $\mathrm{CO}$ and $\mathrm{CO}_{2}$ gas sensors is an effective way to monitor the insulation performance of oil-immersed equipment. The gas sensors based on rGO (Hafiz et al., 2014; Panda et al., 2016; Wu et al., 2016) can lower the operating temperature to room temperature. The graphene metal oxide hybrid materials such as $\mathrm{NiO}$ /graphene (Khaleed et al., 2017), CuO/rGO (Zhang et al., 2017a) $\mathrm{ZnO}$ (Ha et al., 2018), can detect CO with low LOD (as low as $1 \mu \mathrm{L} / \mathrm{L}$ ), and quick response and recovery time (9 s/10 s). Balamurugan et al. (2016) demonstrated a selective $\mathrm{CO}$ sensor based on rGO decorated mesoporous hierarchical
$\mathrm{GaInO}_{3}$, which exhibited a high response rate of $48 \%$ to 20 $\mu \mathrm{L} / \mathrm{L} \mathrm{CO}$ and appreciably fast response $(\sim 14 \mathrm{~s})$ and recovery $(\sim 15 \mathrm{~s})$ at $90^{\circ} \mathrm{C}$. Shojaee and co-workers synthesized Pd-loaded $\mathrm{SnO}_{2} /$ rGO hybrid materials by a hydrothermal method for $\mathrm{CO}$ sensing application (Shojaee et al., 2018). Additionally, much research on $\mathrm{CO}_{2}$ sensor based on graphene hybrid materials have been carried out by Nemade's group. They have fabricated sensors with excellent stability, low LOD and short response and recovery time within $30 \mathrm{~s}$ based on $\mathrm{Sb}_{2} \mathrm{O}_{3}$ quantum dots (QDs)/graphene (Nemade and Waghuley, 2014b), $\mathrm{Al}_{2} \mathrm{O}_{3}$ QDs/graphene (Nemade and Waghuley, 2014a), and $\mathrm{Y}_{2} \mathrm{O}_{3}$ QDs/graphene (Nemade and Waghuley, 2013).

\section{Hydrocarbon Gas}

The hydrocarbon gas $\left(\mathrm{CH}_{4}, \mathrm{C}_{2} \mathrm{H}_{2}, \mathrm{C}_{2} \mathrm{H}_{4}\right.$, and $\left.\mathrm{C}_{2} \mathrm{H}_{6}\right)$ may be generated when electrical or thermal failures occur, such as oil or high-temperature overheating, partial discharge, spark discharge, or arc discharge. These four hydrocarbon gases have a small difference in molecular structure and chemical composition, and the sensing materials usually have the similar response to them. According to the relationship between principle gases and associated fault types (Bakar et al., 2014), when the oil-immersed equipment is suffering an electric or heating fault under any condition, the produced hydrocarbon fault characteristics gas 
TABLE 1 | Summary of recent researches on graphene hybrid materials sensor for sensing of fault characteristic gases in oil-immersed equipment.

\begin{tabular}{|c|c|c|c|c|c|c|c|c|}
\hline Gas & Hybrid material & $\begin{array}{l}\text { Temp. } \\
\left({ }^{\circ} \mathrm{C}\right)\end{array}$ & $\begin{array}{c}\text { Detection } \\
\text { range }(\mu \mathrm{L} / \mathrm{L})\end{array}$ & $\begin{array}{l}\text { Conc. } \\
\text { ( } \mu \mathrm{L} / \mathrm{L})\end{array}$ & $\begin{array}{l}\text { Response } \\
\text { type }\end{array}$ & $\begin{array}{l}\text { Sensor } \\
\text { response }\end{array}$ & $\tau_{\text {res }} / \tau_{\text {rec }}(\mathbf{s} / \mathbf{s})$ & References \\
\hline \multirow[t]{6}{*}{$\mathrm{H}_{2}$} & $\mathrm{Pd} / \mathrm{G}$ & $\mathrm{RT}$ & 1,000 & 1,000 & $\Delta G / G_{\text {air }}$ & $26 \%$ & $40 / 490$ & Alfano et al., 2017 \\
\hline & $\mathrm{Pt} / \mathrm{G}$ & 320 & $1,000-20,000$ & 10,000 & $\Delta R / R_{\text {air }}$ & $1.6 \%$ & $\sim 1 / 0.72$ & Harley-Trochimczyk et al., 2015 \\
\hline & $\mathrm{Pd} / \mathrm{Ag} / \mathrm{G}$ & 105 & $100-5,000$ & 500 & $\Delta R / R_{\text {air }}$ & $9.96 \%$ & $102 /-$ & Sharma and Kim, 2018 \\
\hline & $\mathrm{MoO}_{3} / \mathrm{G}$ & $\mathrm{RT}$ & $0.5-1,000$ & 1,000 & $R_{\text {air }} / R_{\text {gas }}$ & 20.5 & $\sim 10 / 30$ & Yang et al., 2017 \\
\hline & $\mathrm{CuO} / \mathrm{rGO} / \mathrm{CuO}$ & $\mathrm{RT}$ & $50-1,500$ & 100 & $\Delta R / R_{\text {air }}$ & $4.2 \%$ & $<80 / 60$ & Zhang et al., 2017c \\
\hline & $\mathrm{Pd} / \mathrm{WO}_{3} / \mathrm{G}$ & RT & $1,000-5,0000$ & 1,000 & $\Delta l$ & $12 \mu \mathrm{A}$ & $\sim 17 /-$ & Chen et al., 2018 \\
\hline \multirow[t]{6}{*}{$\mathrm{CO}$} & rGO & $\mathrm{RT}$ & $10-30$ & 30 & $\Delta R / R_{\text {air }}$ & $\sim 71 \%$ & $<30 /-$ & Panda et al., 2016 \\
\hline & $\mathrm{NiO} / \mathrm{G}$ & 100 & $5-100$ & 100 & $\Delta R / R_{\text {air }}$ & $\sim 120 \%$ & 20/152 & Khaleed et al., 2017 \\
\hline & $\mathrm{CuO} / \mathrm{rGO}$ & $\mathrm{RT}$ & $0.25-1,000$ & 1 & $\Delta R / R_{\text {air }}$ & $2.56 \%$ & $70 / 160$ & Zhang et al., 2017a \\
\hline & $\mathrm{ZnO} / \mathrm{rGO}$ & 200 & $1-1,000$ & 1,000 & $\Delta R / R_{\text {air }}$ & $85.2 \%$ & $9 / 10$ & Ha et al., 2018 \\
\hline & $\mathrm{GdlnO}_{3} / \mathrm{rGO}$ & 90 & $20-100$ & 20 & $\Delta R / R_{\text {gas }}$ & $48 \%$ & $14 / 15$ & Balamurugan et al., 2016 \\
\hline & $\mathrm{Pd} / \mathrm{SnO}_{2} / \mathrm{rGO}$ & $\mathrm{RT}$ & $50-1,600$ & 1,500 & $\Delta R / R_{\text {air }}$ & $4 \%$ & $70 / 80$ & Shojaee et al., 2018 \\
\hline \multirow[t]{5}{*}{$\mathrm{CO}_{2}$} & rGO & $\mathrm{RT}$ & $100-1,000$ & 1000 & $\Delta R / R_{\text {air }}$ & $1.65 \%$ & - & Nemade and Waghuley, 2014b \\
\hline & rGO & RT & $0-1,500$ & 1,500 & $\Delta R / R_{\text {air }}$ & $71 \%$ & $\sim 4 \min$ & Nemade and Waghuley, 2014a \\
\hline & $\mathrm{Sb}_{2} \mathrm{O}_{3} / \mathrm{G}$ & $\mathrm{RT}$ & $0-50$ & 50 & $\Delta R / R_{\text {air }}$ & $\sim 22 \%$ & $16 / 22$ & Wu et al., 2016 \\
\hline & $\mathrm{Al}_{2} \mathrm{O}_{3} / \mathrm{G}$ & 125 & 0-200 & 100 & $\Delta R / R_{\text {air }}$ & $\sim 8.1 \%$ & $14 / 22$ & Hafiz et al., 2014 \\
\hline & $\mathrm{Y}_{2} \mathrm{O}_{3} / \mathrm{G}$ & $\mathrm{RT}$ & $0-35$ & 35 & $\Delta R / R_{\text {air }}$ & $1.08 \%$ & - & Nemade and Waghuley, 2013 \\
\hline \multirow[t]{5}{*}{$\mathrm{CH}_{4}$} & $\mathrm{PANI} / \mathrm{rG}$ & $\mathrm{RT}$ & $10-3,200$ & 100 & $R_{\text {air }} / R_{\text {gas }}$ & $\sim 3$ & $85 / 45$ & Wu et al., 2013 \\
\hline & $\mathrm{NiO} / \mathrm{rGO}$ & 260 & $100-6,000$ & 100 & $\Delta R / R_{\text {air }}$ & $\sim 2.2 \%$ & $6 / 16$ & Zhang et al., 2016 \\
\hline & $\mathrm{ZnO} / \mathrm{rGO}$ & 190 & $100-4,000$ & 1000 & $\Delta R / R_{\text {air }}$ & $\sim 12 \%$ & $\sim 200$ & Zhang et al., 2015b \\
\hline & $\mathrm{SnO}_{2} / \mathrm{rGO}$ & 150 & $1,000-10,000$ & 1000 & $\Delta R / R_{\text {air }}$ & $47.6 \%$ & $61 / 330$ & Navazani et al., 2018 \\
\hline & $\mathrm{Pd} / \mathrm{SnO}_{2} / \mathrm{rGO}$ & $\mathrm{RT}$ & $800-16,000$ & 14,000 & $\Delta R / R_{\text {air }}$ & $9.8 \%$ & $5 / 7 \min$ & Nasresfahani et al., 2017 \\
\hline \multirow[t]{3}{*}{$\mathrm{C}_{2} \mathrm{H}_{2}$} & $\mathrm{SnO}_{2} / \mathrm{rGO}$ & 180 & $0.5-500$ & 50 & $R_{\text {air }} / R_{\text {gas }}$ & 12.4 & $54 / 23$ & Jin et al., 2016 \\
\hline & $\mathrm{Ag} / \mathrm{ZnO} / \mathrm{rGO}$ & 150 & $1-1,000$ & 100 & $R_{\text {air }} / R_{\text {gas }}$ & 21.2 & $25 / 80$ & Uddin et al., 2015b \\
\hline & $\mathrm{Ag} / \mathrm{SnO}_{2} / \mathrm{rGO}$ & 90 & $5-500$ & 50 & $\Delta R / R_{\text {air }}$ & 15.44 & $235 / 160$ & Jiang et al., 2017 \\
\hline
\end{tabular}

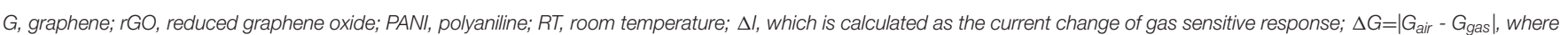

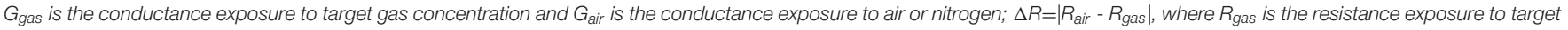
gas concentration and $R_{\text {air }}$ is the resistance exposure to air or nitrogen.

is mainly $\mathrm{CH}_{4}$ or $\mathrm{C}_{2} \mathrm{H}_{2}$, and the amount of each of them is larger than high molecular weight gases $\left(\mathrm{C}_{2} \mathrm{H}_{4}\right.$ and $\left.\mathrm{C}_{2} \mathrm{H}_{6}\right)$ (Sun et al., 2017). Moreover, the detection of $\mathrm{CH}_{4}$ or $\mathrm{C}_{2} \mathrm{H}_{2}$ is becoming more and more important in many fields as the mining industry, environment monitoring and petrochemical industry. Therefore, the research on the detection of hydrocarbon gas in oil-immersed equipment is mainly focused on $\mathrm{CH}_{4}$ and $\mathrm{C}_{2} \mathrm{H}_{2}$. Wu et al. reported a $\mathrm{CH}_{4}$ sensor based on polyaniline (PANI)/graphene. Due to the existence of the $\pi-\pi^{*}$ conjugation system within the PANI/graphene, this sensor showed a high sensitivity of 10-3,200 $\mathrm{L} / \mathrm{L}$ at room temperature (Wu et al., 2013). Zhang et al. (2016) prepared NiO/rGO hybrid materials and demonstrated a high selectivity toward $\mathrm{CH}_{4}$ against $\mathrm{H}_{2}$, $\mathrm{CO}$, and $\mathrm{CO}_{2}$. The response to $100 \mu \mathrm{L} / \mathrm{L} \mathrm{CH}_{4}$ was $2.2 \%$ at $260^{\circ} \mathrm{C}$. Graphene hybrid with $\mathrm{ZnO}$ (Zhang et al., 2015b) and $\mathrm{SnO}_{2}$ (Navazani et al., 2018) also exhibited unique sensing properties to $\mathrm{CH}_{4}$ around 190 and $150^{\circ} \mathrm{C}$. Nasresfahani et al. (2017) synthesized $\mathrm{Pd}$-doped $\mathrm{SnO}_{2} / \mathrm{rGO}$ via hydrothermal route, and the sensing performance to $800-16,000 \mu \mathrm{L} / \mathrm{L} \mathrm{CH}_{4}$ were carried out at room temperature. Gas sensing characteristics of $\mathrm{C}_{2} \mathrm{H}_{2}$ sensor based on $\mathrm{SnO}_{2} / \mathrm{rGO}$ were carried out for $0.5-500$ $\mu \mathrm{L} / \mathrm{L} \mathrm{C}_{2} \mathrm{H}_{2}$ at $180^{\circ} \mathrm{C}$. The $p-n$ heterojunctions between $\mathrm{SnO}_{2}$ and $\mathrm{rGO}$, oxygen functional groups and high specific surface area of $\mathrm{SnO}_{2} / \mathrm{rGO}$ hybrid materials contribute to the high performance of sensor (Jin et al., 2016). Furthermore, Ag/ZnO/rGO (Uddin et al., 2015b) and $\mathrm{Ag} / \mathrm{SnO}_{2} / \mathrm{rGO}$ (Jiang et al., 2017) hybrid materials were synthesized, and the sensors were developed for low-temperature $\mathrm{C}_{2} \mathrm{H}_{2}$ sensing. However, with the decrease of operating temperature, the sensitivity of the sensor was reduced with longer response-recovery time.

\section{CONCLUSIONS}

Graphene hybrids are distinctive and promising sensing materials for detection of various gases, due to their ultrahigh electron mobility and large specific surface area. Compared to other types of sensor, the graphene-based sensors exhibit 
excellent properties and provide a new idea for high sensitivity detection of the oil-immersed power equipment at low temperature.

Although great progress has been made in this field, there are still many challenges that need to be addressed. First, lower LOD and faster response-recovery time are needed. Graphenebased sensors provide a possible approach to detect gases at room temperature, but the reaction activities between gas molecules and sensing materials may be reduced, especially during the desorption, making it difficult to meet the engineering requirements. Ultraviolet light assisted excitation technology and novel multi-dimensional hierarchical nanostructure of graphene hybrid materials are useful ways to solve this problem. Secondly, avoiding the cross-sensitivity in the detection of mixed gas. Gas sensors usually exhibit similar responses toward different gases of different concentrations. The functionalization of graphene, operating temperature modulation and design of filter layer are workable methods to overcome this challenge. Moreover, gas sensor arrays, composed of group of sensors and signal processing algorithms, can realize the qualitative identification and quantitative detection of mixed gas. Thirdly, developing more stable materials and sensors. In practical application, the condition of detection environment, such

\section{REFERENCES}

Acharyya, D., and Bhattacharyya, P. (2016). Highly efficient room-temperature gas sensor based on $\mathrm{TiO}_{2}$ nanotube-reduced graphene-oxide hybrid device. IEEE Electron Device Lett. 37, 656-659. doi: 10.1109/LED.2016.25 44954

Aïssa, B., Memon, N. K., Ali, A., and Khraisheh, M. K. (2015). Recent progress in the growth and applications of graphene as a smart material: a review. Front. Mater 2:58. doi: 10.3389/fmats.2015.00058

Akturk, A., and Goldsman, N. (2008). Electron transport and full-band electron-phonon interactions in graphene. J. Appl. Phys. 103:053702. doi: 10.1063/1.2890147

Alfano, B., Massera, E., Polichetti, T., Miglietta, M. L., and Di Francia, G. (2017). Effect of palladium nanoparticle functionalization on the hydrogen gas sensing of graphene based chemi-resistive devices. Sensors Actuat. B Chem. 253, 1163-1169. doi: 10.1016/j.snb.2017.07.146

Bai, S., Chen, C., Luo, R., Chen, A., and Li, D. (2015). Synthesis of $\mathrm{MoO} 3 /$ reduced graphene oxide hybrids and mechanism of enhancing H2S sensing performances. Sensors Actuat. B Chem. 216, 113-120. doi: 10.1016/j.snb.2015.04.036

Bakar, N., Abu-Siada, A., and Islam, S. (2014). A review of dissolved gas analysis measurement and interpretation techniques. IEEE Electric. Insulation Magaz. 30, 39-49. doi: 10.1109/MEI.2014.6804740

Balamurugan, C., Arunkumar, S., and Lee, D.-W. (2016). Hierarchical 3D nanostructure of $\mathrm{GdInO} 3$ and reduced-graphene-decorated GdInO3 nanocomposite for $\mathrm{CO}$ sensing applications. Sensors Actuat. B Chem. 234, 155-166. doi: 10.1016/j.snb.2016.04.043

Banszerus, L., Schmitz, M., Engels, S., Dauber, J., Oellers, M., Haupt, F., et al. (2015). Ultrahigh-mobility graphene devices from chemical vapor deposition on reusable copper. Sci. Adv. 1:e1500222. doi: 10.1126/sciadv.1500222

Barsan, N., and Weimar, U. (2003). Understanding the fundamental principles of metal oxide based gas sensors; the example of $\mathrm{CO}$ sensing with $\mathrm{SnO}_{2}$ sensors in the presence of humidity. J. Phys. Condens. Matter 15, R813. doi: 10.1088/0953-8984/15/20/201

Bonaccorso, F., Colombo, L., Yu, G., Stoller, M., Tozzini, V., Ferrari, A. C., et al. (2015). Graphene, related two-dimensional crystals, and hybrid systems for energy conversion and storage. Science 347:1246501. doi: $10.1126 /$ science. 1246501 as vibration, temperature, humidity, and other contaminants, may affect the sensitivity of sensors. The improvement of sensing materials, coating method, and fabrication techniques can avoid or reduce the impact of these factors. Finally, the development in this field is inseparable from the research of new materials as well as the corresponding sensing mechanism.

\section{AUTHOR CONTRIBUTIONS}

WC and LJ summarized and analyzed the related literature. LJ wrote the manuscript under the guidance of $\mathrm{YZ}$ and WC. All authors read and approved the manuscript.

\section{ACKNOWLEDGMENTS}

This study was supported by the Science Fund for Creative Research Groups of the National Natural Science Foundation of China (Grant No. 51321063) and the Joint Fund of the National Natural Science Foundation of China and the Smart Grid of State Grid Corporation of China (Grant No. U1766217). LJ thanks the China Scholarship Council (CSC) project (201706050039) for financial support.
Chen, J.-H., Jang, C., Xiao, S., Ishigami, M., and Fuhrer, M. S. (2008). Intrinsic and extrinsic performance limits of graphene devices on $\mathrm{SiO}_{2}$. Nat. Nanotechnol. 3 , 206. doi: 10.1038/nnano.2008.58

Chen, M., Zou, L., Zhang, Z., Shen, J., Li, D., Zong, Q., et al. (2018). Tandem gasochromic-Pd- $\mathrm{WO}_{3} /$ graphene/Si device for room-temperature high-performance optoelectronic hydrogen sensors. Carbon 130, 281-287. doi: 10.1016/j.carbon.2018.01.013

Dai, Y., Liu, Y., Ding, K., and Yang, J. (2018). A short review of nanographenes: structures, properties and applications. Mol. Phys. 116, 987-1002. doi: 10.1080/00268976.2018.1433881

Esfandiar, A., Irajizad, A., Akhavan, O., Ghasemi, S., and Gholami, M. R. (2014). Pd-WO3/reduced graphene oxide hierarchical nanostructures as efficient hydrogen gas sensors. Int. J. Hydrogen Energy 39, 8169-8179. doi: 10.1016/j.ijhydene.2014.03.117

Geim, A. K., and Novoselov, K. S. (2007). The rise of graphene. Nat. Mater. 6, 183. doi: 10.1038/nmat1849

Ha, N. H., Thinh, D. D., Huong, N. T., Phuong, N. H., Thach, P. D., and Hong, H. S. (2018). Fast response of carbon monoxide gas sensors using a highly porous network of $\mathrm{ZnO}$ nanoparticles decorated on $3 \mathrm{D}$ reduced graphene oxide. Appl. Surf. Sci. 434, 1048-1054. doi: 10.1016/j.apsusc.2017. 11.047

Hafiz, S. M., Ritikos, R., Whitcher, T. J., Razib, N. M., Bien, D. C. S., Chanlek, N., et al. (2014). A practical carbon dioxide gas sensor using room-temperature hydrogen plasma reduced graphene oxide. Sensors Actuat. B Chem. 193, 692-700. doi: 10.1016/j.snb.2013.12.017

Harley-Trochimczyk, A., Chang, J., Zhou, Q., Dong, J., Pham, T., Worsley, M. A., et al. (2015). Catalytic hydrogen sensing using microheated platinum nanoparticle-loaded graphene aerogel. Sensors Actuat B Chem. 206, 399-406. doi: 10.1016/j.snb.2014.09.057

Higgins, D., Zamani, P., Yu, A., and Chen, Z. (2016). The application of graphene and its composites in oxygen reduction electrocatalysis: a perspective and review of recent progress. Energy Environ. Sci. 9, 357-390. doi: 10.1039/C5EE02474A

Hofmann, M., Chiang, W.-Y., Nguyễn, T. D., and Hsieh, Y.-P. (2015). Controlling the properties of graphene produced by electrochemical exfoliation. Nanotechnology 26:335607. doi: 10.1088/0957-4484/26/33/335607

Jiang, C., Zhang, D., Yin, N., Yao, Y., Shaymurat, T., and Zhou, X. (2017). Acetylene gas-sensing properties of layer-by-layer self-assembled 
Ag-decorated tin dioxide/graphene nanocomposite film. Nanomaterials 7, 278. doi: $10.3390 /$ nano7090278

Jin, L., Chen, W., Zhang, H., Xiao, G., Yu, C., and Zhou, Q. (2016). Characterization of Reduced Graphene Oxide (rGO)-loaded $\mathrm{SnO}_{2}$ nanocomposite and applications in $\mathrm{C}_{2} \mathrm{H}_{2}$ gas detection. Appl. Sci. 7, 19. doi: 10.3390/app7010019

Khaleed, A., Bello, A., Dangbegnon, J., Madito, M., Ugbo, F., Akande, A., et al. (2017). Gas sensing study of hydrothermal reflux synthesized $\mathrm{NiO} /$ graphene foam electrode for CO sensing. J. Mater. Sci. 52, 2035-2044. doi: 10.1007/s10853-016-0491-6

Long, H., Zeng, W., Wang, H., Qian, M., Liang, Y., and Wang, Z. (2018). Selfassembled biomolecular 1D nanostructures for aqueous sodium-ion battery. Adv. Sci. 5:1700634. doi: 10.1002/advs.201700634

Meng, F.-L., Guo, Z., and Huang, X.-J. (2015). Graphene-based hybrids for chemiresistive gas sensors. TrAC Trends Anal. Chem. 68, 37-47. doi: 10.1016/j.trac.2015.02.008

Nasresfahani, S., Sheikhi, M., Tohidi, M., and Zarifkar, A. (2017). Methane gas sensing properties of $\mathrm{Pd}$-doped $\mathrm{SnO} 2 /$ reduced graphene oxide synthesized by a facile hydrothermal route. Mater. Res. Bull. 89, 161-169. doi: 10.1016/j.materresbull.2017.01.032

Navazani, S., Shokuhfar, A., Hassanisadi, M., Askarieh, M., Di Carlo, A., and Agresti, A. (2018). Facile synthesis of a $\mathrm{SnO}_{2} @$ rGO nanohybrid and optimization of its methane-sensing parameters. Talanta 181, 422-430. doi: 10.1016/j.talanta.2018.01.015

Nemade, K., and Waghuley, S. (2013). "Carbon dioxide gas sensing application of graphene $/ \mathrm{Y}_{2} \mathrm{O}_{3}$ quantum dots composite," Paper presented at the International Journal of Modern Physics: Conference Series (Bikaner).

Nemade, K., and Waghuley, S. (2014a). Highly responsive carbon dioxide sensing by graphene $/ \mathrm{Al}_{2} \mathrm{O}_{3}$ quantum dots composites at low operable temperature. Indian J. Phys. 88, 577-583. doi: 10.1007/s12648-014-0454-1

Nemade, K., and Waghuley, S. (2014b). Role of defects concentration on optical and carbon dioxide gas sensing properties of $\mathrm{Sb}_{2} \mathrm{O}_{3} /$ graphene composites. Opt. Mater. 36, 712-716. doi: 10.1016/j.optmat.2013.11.024

Nguyen, H., Quy, C. T., Hoa, N. D., Van Duy, N., Van Quang, V., and Van Hieu, N. (2014). Controllable growth of $\mathrm{ZnO}$ nanowires grown on discrete islands of Au catalyst for realization of planar-type micro gas sensors. Sensors Actuat. B Chem. 193, 888-894. doi: 10.1016/j.snb.2013.11.043

Novoselov, K. S., Geim, A. K., Morozov, S. V., Jiang, D., Zhang, Y., Dubonos, S. V., et al. (2004). Electric field effect in atomically thin carbon films. Science, 306, 666-669. doi: 10.1126/science.1102896

Ozcan, S., Vempati, S., Çirpan, A., and Uyar, T. (2018). Associative behaviour and effect of functional groups on the fluorescence of graphene oxide. Phys. Chem. Chem. Phys. 20, 7559-7569. doi: 10.1039/C7CP08334C

Panda, D., Nandi, A., Datta, S. K., Saha, H., and Majumdar, S. (2016). Selective detection of carbon monoxide (CO) gas by reduced graphene oxide (rGO) at room temperature. RSC Adv. 6, 47337-47348. doi: 10.1039/C6RA06058G

Paton, K. R., Varrla, E., Backes, C., Smith, R. J., Khan, U., O’Neill, A., et al. (2014). Scalable production of large quantities of defect-free few-layer graphene by shear exfoliation in liquids. Nat. Mater. 13, 624. doi: 10.1038/nmat3944

Phan, D.-T., Youn, J.-S., and Jeon, K.-J. (in press). High-sensitivity and fastresponse hydrogen sensor for safety application using Pt nanoparticledecorated 3D graphene. Renewable Energy. doi: 10.1016/j.renene.2018.05.033.

Prezioso, S., Perrozzi, F., Giancaterini, L., Cantalini, C., Treossi, E., Palermo, V., et al. (2013). Graphene oxide as a practical solution to high sensitivity gas sensing. J. Phys. Chem. C 117, 10683-10690. doi: 10.1021/jp30 85759

Quan, B., Yu, S.-H., Chung, D. Y., Jin, A., Park, J. H., Sung, Y.-E., et al. (2014). Single source precursor-based solvothermal synthesis of heteroatom-doped graphene and its energy storage and conversion applications. Sci. Rep. 4:5639. doi: $10.1038 /$ srep05639

Russo, P. A., Donato, N., Leonardi, S. G., Baek, S., Conte, D. E., Neri, G., et al. (2012). Room-temperature hydrogen sensing with heteronanostructures based on reduced graphene oxide and tin oxide. Angewand. Chem. Int. Ed. 51, 11053-11057. doi: 10.1002/anie.201204373

Schedin, F., Geim, A., Morozov, S., Hill, E., Blake, P., Katsnelson, M., et al. (2007). Detection of individual gas molecules adsorbed on graphene. Nat. Mater. 6, 652. doi: $10.1038 /$ nmat1967
Sharma, B., and Kim, J.-S. (2018). Graphene decorated Pd-Ag nanoparticles for $\mathrm{H}_{2}$ sensing. Int. J. Hydrogen Energy 43, 11397-11402. doi: 10.1016/j.ijhydene.2018.03.026

Shojaee, M., Nasresfahani, S., and Sheikhi, M. (2018). Hydrothermally synthesized $\mathrm{Pd}$-loaded $\mathrm{SnO}_{2} /$ partially reduced graphene oxide nanocomposite for effective detection of carbon monoxide at room temperature. Sensors Actuat. B Chem. 254, 457-467. doi: 10.1016/j.snb.2017.07.083

Singhal, A. V., Charaya, H., and Lahiri, I. (2017). Noble metal decorated graphenebased gas sensors and their fabrication: a review. Crit. Rev. Solid State Mater. Sci. 42, 499-526. doi: 10.1080/10408436.2016.1244656

Son, I. H., Park, J. H., Kwon, S., Park, S., Rümmeli, M. H., Bachmatiuk, A., et al. (2015). Silicon carbide-free graphene growth on silicon for lithiumion battery with high volumetric energy density. Nat. Commun. 6:8393. doi: $10.1038 /$ ncomms 8393

Sun, C., Ohodnicki, P. R., and Stewart, E. M. (2017). Chemical sensing strategies for real-time monitoring of transformer oil: a review. IEEE Sensors J. 17, 5786-5806. doi: 10.1109/JSEN.2017.2735193

Sun, R., Wang, Z., Saito, M., Shibata, N., and Ikuhara, Y. (2015). Atomistic mechanisms of nonstoichiometry-induced twin boundary structural transformation in titanium dioxide. Nat. Commun. 6, 7120. doi: $10.1038 /$ ncomms 8120

Tran, Q. T., Hoa, H. T. M., Yoo, D.-H., Cuong, T. V., Hur, S. H., Chung, J. S., et al. (2014). Reduced graphene oxide as an over-coating layer on silver nanostructures for detecting $\mathrm{NH}_{3}$ gas at room temperature. Sensors Actuat. $B$ Chem. 194, 45-50. doi: 10.1016/j.snb.2013.12.062

Uddin, A. I., Lee, K.-W., and Chung, G.-S. (2015a). Acetylene gas sensing properties of an Ag-loaded hierarchical $\mathrm{ZnO}$ nanostructure-decorated reduced graphene oxide hybrid. Sensors Actuat. B Chem. 216, 33-40. doi: 10.1016/j.snb.2015.04.028

Uddin, A. I., Phan, D.-T., and Chung, G.-S. (2015b). Low temperature acetylene gas sensor based on Ag nanoparticles-loaded $\mathrm{ZnO}$-reduced graphene oxide hybrid. Sensors Actuat. B Chem. 207, 362-369. doi: 10.1016/j.snb.2014.10.091

Wang, S., Yang, J., Zhang, H., Wang, Y., Gao, X., Wang, L., et al. (2015). One-pot synthesis of 3D hierarchical $\mathrm{SnO}_{2}$ nanostructures and their application for gas sensor. Sensors Actuat. B Chem. 207, 83-89. doi: 10.1016/j.snb.2014.10.032

Wang, T., Huang, D., Yang, Z., Xu, S., He, G., Li, X., et al. (2016). A review on graphene-based gas/vapor sensors with unique properties and potential applications. Nano Micro Lett. 8, 95-119. doi: 10.1007/s40820-015-0073-1

Wang, Z., Saito, M., McKenna, K. P., Fukami, S., Sato, H., Ikeda, S., et al. (2016). Atomic-Scale structure and local chemistry of $\mathrm{COFeB}-\mathrm{MgO}$ magnetic tunnel junctions. Nano Lett. 16, 1530-1536. doi: 10.1021/acs.nanolett.5b03627

Wang, Z., Saito, M., McKenna, K. P., Gu, L., Tsukimoto, S., Shluger, A. L., et al. (2011). Atom-resolved imaging of ordered defect superstructures at individual grain boundaries. Nature 479, 380. doi: 10.1038/nature10593

Wei, Y., Yi, G., Xu, Y., Zhou, L., Wang, X., Cao, J., et al. (2017). Synthesis, characterization, and gas-sensing properties of $\mathrm{Ag} / \mathrm{SnO}_{2} / \mathrm{rGO}$ composite by a hydrothermal method. J. Mater. Sci. Mater. Electron. 28, 17049-17057. doi: 10.1007/s10854-017-7630-y

Wu, J., Tao, K., Zhang, J., Guo, Y., Miao, J., and Norford, L. K. (2016). Chemically functionalized 3D graphene hydrogel for high performance gas sensing. J. Mater. Chem. A 4, 8130-8140. doi: 10.1039/C6TA01426G

Wu, Z., Chen, X., Zhu, S., Zhou, Z., Yao, Y., Quan, W., et al. (2013). Room temperature methane sensor based on graphene nanosheets/polyaniline nanocomposite thin film. IEEE Sensors J. 13, 777-782. doi: 10.1109/JSEN.2012.2227597

Yang, S., Wang, Z., Zou, Y., Luo, X., Pan, X., Zhang, X., et al. (2017). Remarkably accelerated room-temperature hydrogen sensing of $\mathrm{MoO}$ 3 nanoribbon/graphene composites by suppressing the nanojunction effects. Sensors Actuat. B Chem. 248, 160-168. doi: 10.1016/j.snb.2017. 03.106

Ye, R., Peng, Z., Wang, T., Xu, Y., Zhang, J., Li, Y., et al. (2015). In situ formation of metal oxide nanocrystals embedded in laser-induced graphene. Acs Nano 9 , 9244-9251. doi: 10.1021/acsnano.5b04138

Yola, M. L., Atar, N., Eren, T., Karimi-Maleh, H., and Wang, S. (2015). Sensitive and selective determination of aqueous triclosan based on gold nanoparticles on polyoxometalate/reduced graphene oxide nanohybrid. RSC Adv. 5, 65953-65962. doi: 10.1039/C5RA07443F 
Zhang, B., Liu, J., Cui, X., Wang, Y., Gao, Y., Sun, P., et al. (2017). Enhanced gas sensing properties to acetone vapor achieved by $\alpha-\mathrm{Fe} 2 \mathrm{O} 3$ particles ameliorated with reduced graphene oxide sheets. Sensors Actuat. B Chem. 241, 904-914. doi: 10.1016/j.snb.2016.11.023

Zhang, D., Chang, H., Li, P., and Liu, R. (2016). Characterization of nickel oxide decorated-reduced graphene oxide nanocomposite and its sensing properties toward methane gas detection. J. Mater. Sci. Mater. Electron. 27, 3723-3730. doi: 10.1007/s10854-015-4214-6

Zhang, D., Jiang, C., Liu, J., and Cao, Y. (2017a). Carbon monoxide gas sensing at room temperature using copper oxide-decorated graphene hybrid nanocomposite prepared by layer-by-layer selfassembly. Sensors Actuat. B Chem. 247, 875-882. doi: 10.1016/j.snb.2017. 03.108

Zhang, D., Jiang, C., Yin, N., and Xia, B. (2017b). Sensing characteristics of acetylene gas in transformer oil of nano-modified graphene-based film sensor. High Voltage Eng. 11, 029. doi: 10.13336/j.1003-6520.hve.201710 31029

Zhang, D., Liu, A., Chang, H., and Xia, B. (2015a). Room-temperature highperformance acetone gas sensor based on hydrothermal synthesized $\mathrm{SnO}$ 2-reduced graphene oxide hybrid composite. RSC Adv. 5, 3016-3022. doi: 10.1039/C4RA10942B

Zhang, D., Yin, N., Jiang, C., and Xia, B. (2017c). Characterization of $\mathrm{CuO}$-reduced graphene oxide sandwiched nanostructure and its hydrogen sensing characteristics. J. Mater. Sci. Mater. Electron. 28, 2763-2768. doi: 10.1007/s10854-016-5856-8

Zhang, D., Yin, N., and Xia, B. (2015b). Facile fabrication of ZnO nanocrystalline-modified graphene hybrid nanocomposite toward methane gas sensing application. J. Mater. Sci. Mater. Electron. 26, 5937-5945. doi: 10.1007/s10854-015-3165-2

Zhang, Y., Zeng, W., Ye, H., and Li, Y. (2018). Enhanced carbon monoxide sensing properties of $\mathrm{TiO} 2$ with exposed $\left(\begin{array}{lll}0 & 0 & 1\end{array}\right)$ facet: a combined first-principle and experimental study. Appl. Surf. Sci. 442, 507-516. doi: 10.1016/j.apsusc.2018.02.036

Zhou, Q., Jin, L., Chen, W., Li, J., and Zeng, W. (2016). Detection of hydrogen at room temperature based on Au@ rGO composites chemical sensor. Sensor Lett. 14, 961-966. doi: 10.1166/sl.2016.3719

Zhou, Y., Lin, X., Wang, Y., Liu, G., Zhu, X., Huang, Y., et al. (2017). Study on gas sensing of reduced graphene oxide/ $\mathrm{ZnO}$ thin film at room temperature. Sensors Actuat B Chem. 240, 870-880. doi: 10.1016/j.snb.2016. 09.064

Zhu, L., and Zeng, W. (2017). A novel coral rock-like $\mathrm{ZnO}$ and its gas sensing. Mater. Lett. 209, 244-246. doi: 10.1016/j.matlet.2017. 08.020

Conflict of Interest Statement: The authors declare that the research was conducted in the absence of any commercial or financial relationships that could be construed as a potential conflict of interest.

Copyright (c) 2018 Jin, Chen and Zhang. This is an open-access article distributed under the terms of the Creative Commons Attribution License (CC BY). The use, distribution or reproduction in other forums is permitted, provided the original author(s) and the copyright owner(s) are credited and that the original publication in this journal is cited, in accordance with accepted academic practice. No use, distribution or reproduction is permitted which does not comply with these terms. 